\title{
Clinical Course and Predictors of Poor Functional Outcome in Guillain-Barré Syndrome. A Retrospective Study
}

\author{
Maha Shangab ${ }^{a}$ Muhammad Al Kaylanib \\ anternal Medicine Department, Rashid Hospital, Dubai Health Authority, Dubai, UAE; \\ ${ }^{b}$ Neurology Department, Rashid Hospital, Dubai Health Authority, Dubai, UAE
}

\section{Keywords}

Disability · Guillian-Barrésyndrome · Neurology ·

Neuromuscular·Predictors

\begin{abstract}
Introduction: Guillain-Barré syndrome (GBS) is the most common cause of acute flaccid paralysis. It carries great morbidity due to an overall high rate of poor functional outcome. This study is conducted to study the predictors of poor functional outcome. Methods: This study a retrospective observational study, which was conducted in Rashid Hospital Tertiary Center in Dubai between 2009 and 2019. Functional status was assessed and followed by the GBS disability score. Functional outcome at 6 months was evaluated for possible predicting factors as well as associated outcomes. Results: Out of the 82 cases, the mean age at presentation is $37 \pm 14.4$, with 64 (78\%) males. Around one-third of cases $(37.8 \%)$ had residual deficits at 6 months. Follow-up after 6 months showed that cases with a poor functional outcome are older $(p=0.035)$ and have presented with a high disability score $(p<0.001)$ and a higher need for mechanical ventilation $(p<0.001)$. Axonal type of nerve injury resulted in poor functional outcome at 6 months compared
\end{abstract}

to the demyelinating type of nerve injury $(p=0.034)$. Lower rate of improvement at 1 month and poor functional outcome at 6 months resulted in a longer hospital stay $(p<$ 0.001). Conclusion: A poor functional status at presentation, axonal type of nerve injury, and the early requirement for mechanical ventilation are found to predict poor functional improvement after 6 months from diagnosis. These factors must be kept in consideration to facilitate more vigilant management of patient's associated high morbidity.

(c) 2020 The Author(s)

Published by S. Karger AG, Basel

\section{Introduction}

Guillain-Barré syndrome (GBS) is the most common cause of acute flaccid paralysis and it can occur at any age. Overall incidence is estimated to be $1.1-1.8 / 100,000 /$ year, which rises after the age of 50 to be $1.7-3.3 / 100,000 /$ year [1]. It is common to cause an acute immune-mediated polyneuropathy, but it may persist in some cases to become chronic inflammatory demyelinating polyneuropathy.

The main methods of therapy for GBS are plasma exchange (PLEX) and administration of intravenous immunoglobulin (IVIG). PLEX is believed to work by re-

\begin{tabular}{ll}
\hline karger@karger.com & (c) 2020 The Author(s) \\
Pww.karger.com/dmj & Published by S. Karger AG, Basel \\
& This article is licensed under the Creative Commons Attribution- \\
NonCommercial-NoDerivatives 4.0 International License (CC BY- \\
NC-ND) (http://www.karger.com/Services/OpenAccessLicense). \\
Usage and distribution for commercial purposes as well as any dis- \\
tribution of modified material requires written permission.
\end{tabular}

Maha Shangab

Internal Medicine Resident, Internal Medicine Department

Rashid Hospital, Dubai Health Authority

Umhurair Road, Dubai 4545 (United Arab Emirates)

Moshangab@dha.gov.ae 
moving intravascular circulating large molecular autoantibodies, immune complexes, cytokines, and other inflammatory mediators responsible for the inflammatory attack in GBS. It does not, however, remove the clustered extravascular inflammatory mediators attacking the myelin sheath and possibly the axons until they are shifted to intravascular space after removing the intravascular mediators by a session of PLEX, hence the need for repeated sessions [2]. IVIG mechanism on the other hand is not fully understood but may include neutralizing the autoantibodies, modulating expression and function of Fc receptors, and interfering with activation of complement and production of cytokines [2,3].

These immunomodulatory treatments halt disease progression and accelerate the recovery of GBS. The beneficial effects of PLEX and IVIG are believed to be equivalent and are advised equally in guidelines $[4,5]$. A Cochrane review in 2014 found no difference between the outcomes of IVIG course and 5 PLEX sessions. The outcome measured in that study included the disability grade after 4 weeks, duration of mechanical ventilation, and mortality [6]. This result was consistent with the outcome of a previous randomized controlled trial done in 1992 [7].

The above-mentioned studies, as well as other studies, suggest that treatment modality used is not a significant contributory factor in the functional outcome. Other factors might be more predictive of the functional outcome of patients with GBS. A prognostic scoring method was developed in a Dutch prospective cohort to test the probability of being unable to walk independently during the first 6 months of follow-up. This model depends on 3 factors, the age, presence of history of diarrhea, and the disability score at 2 weeks [8], which was later modified to disability score at 1 week [9].

Our current study assesses the patient-related and disease-related characteristics and compares them to shortand long-term functional outcomes. We aim to fill in the gap of knowledge present regarding the epidemiology and functional outcome prediction in GBS in the ethnically diverse population of Dubai.

\section{Methods and Materials}

\section{Study Design}

The study is a retrospective observational study, which was conducted in Rashid Hospital Tertiary Center in Dubai, UAE. Data included in the study were collected for the cases admitted with GBS from February 2011 to February 2019. Data pertaining to admissions before that period were unobtainable as old physical
0 . A healthy state

1. Minor symptoms and capable of running

2. Able to walk $10 \mathrm{~m}$ or more without assistance but unable to run

3. Able to walk $10 \mathrm{~m}$ across an open space with help

4. Bedridden or chair bound

5. Requiring ventilation for at least part of the day

6. Dead

Fig. 1. GBS disability scale. GBS, Guillain-Barré syndrome [10].

files that dated 5 years and more before the start of the electronic medical records (in 2017) became not accessible. Eighty-six cases were recruited in the study after tracing ICD-10 code 61.0. Cases that did not receive immune-modulating therapy in our center or had unconfirmed diagnosis of GBS were excluded from the study, leaving a total of 82 patients included in the final analysis. Ethical approval was obtained for the study.

\section{Study Procedure}

Data pertaining to recent admissions were extracted from electronic medical records, and older data were retrieved from physical record files when available. Data collected included patientrelated information like age, gender, and preexisting comorbid conditions. Data pertaining to clinical presentation included time since presentation, GBS disability scale at presentation (Fig. 1) [10], as well as the need for mechanical ventilation.

Clinical course was followed by assessing the disability scale periodically since the onset of the illness to trace the rate of progression. This was done at day 0 (day of admission), day 7, day 14, day 28 , and 3 and 6 months when feasible and data are available. Presence of residual deficit at 6 months and at 1 year from the onset of the acute paralysis was recorded. Nerve conduction studies classified nerve damage into acute inflammatory demyelinating polyradiculoneuropathy, acute motor axonal neuropathy, and mixed demyelinating and axonal polyneuropathy. Treatment regimen applied was recorded as well as reported side effects.

\section{Outcomes Measured}

The main objective of the study is to compare the degree of improvement in GBS disability grade ranging from 0 (Normal) to 6 (Death), 4 weeks after the initiation of immune-modulatory therapy as well as to classify and compare the outcome according the functional scale. A good outcome is defined as the ability to ambulate without assistance (GBS disability score $\leq 2$ ); a poor outcome, as the inability to ambulate independently (GBS disability score $\geq 3$ ). Follow-up continued up to 12 months after initial presentation in 49 cases only. For this reason, primary objective was limited to the initial 1 month period, with secondary focus on longterm follow-up.

\section{Statistical Analysis}

Data collected were tabulated in a spreadsheet document, then analyzed by Statistical Package for the Social Sciences (SPSS, 20th version) system. Data were presented when required as mean and SD for bell-shaped numerical data, median and interquartile range [IQR] for skewed numerical data, and frequency (\%) for categorical data.
Shangab/Al Kaylani 


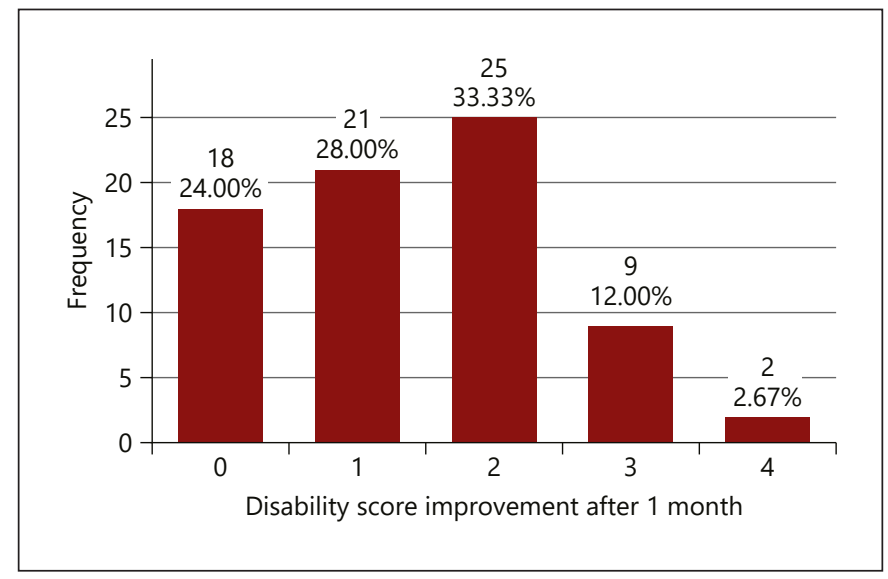

Fig. 2. Disability score improvement after 1 month.

For inferential statistics, data were analyzed using the $\chi^{2}$ test for categorical data comparisons, Spearman's correlations for numerical data, and 1-way ANOVA; the independent-sample KruskalWallis and Mann-Whitney tests were used for comparisons between categorical and numerical data. McNemar's test was performed on paired nominal data as it relates to proportion of cases with good functional status after 1 month and after 6 months.

Variables were tested, when applicable, for the prediction of the following outcomes: (1) degree of improvement in disability score at 4 weeks and (2) functional outcome after 6 months. All tests were 2 -tailed tests with $p$ value significant at $<0.05$ (Fig. 1).

\section{Results}

Of the 82 cases analyzed, $64(78 \%)$ were males. Average age at presentation was $37 \pm 14.4$ years, which ranged between 14 and 80 years. Cases presented to our center were from different ethnic backgrounds, as shown in Table 1. The table demonstrates the clinical presentation of cases, as well as treatment applied and disease-related characteristics. Around one-third of cases (37.8\%) had residual deficit at 6 months, which remained in the same range after a year (34.1\%).

Cases presented with a median disability score of 4 [1]. After a month (Fig. 2), 75 remained for follow-up, and the remainder were discharged and lost to follow-up. The rate of improvement after the first month was 1 [1], with most of the cases showing a 2 disability score improvement after a month as shown in the graph, and only 2 cases showing a significant improvement of 4 disability scores. The rate of improvement from baseline to 1 month and then to 6 months was significant, as demonstrated in Table 2.

Predicting Poor Functional Outcome in GBS
Table 1. Patient- and disease-related characteristics

\begin{tabular}{|c|c|}
\hline \multirow{2}{*}{\multicolumn{2}{|c|}{$\begin{array}{l}\text { Age } \\
\text { Gender }\end{array}$}} \\
\hline & \\
\hline Male & $64(78)$ \\
\hline Female & $18(22)$ \\
\hline \multicolumn{2}{|l|}{ Origin } \\
\hline South Asia & $47(57.3)$ \\
\hline United Arab Emirates National & $14(17.1)$ \\
\hline Middle East and North Africa & $10(12.2)$ \\
\hline African & $4(4.9)$ \\
\hline Others & $7(8.6)$ \\
\hline Days from onset of symptoms until presentation & $3[2]$ \\
\hline \multicolumn{2}{|l|}{ Disability score upon presentation } \\
\hline 1 & $2(2.4)$ \\
\hline 2 & $3(3.7)$ \\
\hline 3 & $24(29.3)$ \\
\hline 4 & $34(41.5)$ \\
\hline 5 & $19(23.2)$ \\
\hline \multicolumn{2}{|l|}{ Requiring intubation } \\
\hline No & $62(75.6)$ \\
\hline Yes & $20(24.4)$ \\
\hline Duration of intubation, days & $22[27]$ \\
\hline Length of hospital stay, days & $17.5[37]$ \\
\hline \multicolumn{2}{|l|}{ Nerve conduction results } \\
\hline Axonal neuropathy & $28(34.1)$ \\
\hline Demyelinating neuropathy & $22(26.8)$ \\
\hline Mixed axonal and demyelinating neuropathy & $16(19.5)$ \\
\hline Normal & $7(8.5)$ \\
\hline \multicolumn{2}{|l|}{ Treatment applied } \\
\hline IVIG & $47(57.3)$ \\
\hline PLEX & $14(17.1)$ \\
\hline IVIG then PLEX & $9(11)$ \\
\hline Repeated IVIG courses & $9(11)$ \\
\hline PLEX then IVIG & $3(3.7)$ \\
\hline \multicolumn{2}{|l|}{ Treatment side effect } \\
\hline Infection & $8(9.8)$ \\
\hline Headache & $7(8.5)$ \\
\hline Allergic reaction & $6(7.3)$ \\
\hline None & $61(74.4)$ \\
\hline \multicolumn{2}{|l|}{ Residual deficit } \\
\hline Deficit at 6 months & Out of 49 \\
\hline Motor & $25(30.5)$ \\
\hline Sensory & $5(6.1)$ \\
\hline Autonomic & $1(1.2)$ \\
\hline Deficit at 1 year & Out of 49 \\
\hline Motor & $23(28)$ \\
\hline Sensory & $4(4.9)$ \\
\hline Autonomic & $1(1.2)$ \\
\hline
\end{tabular}

$N(\%)$, mean $\pm \mathrm{SD}$, median [IQR]. IVIG, intravenous immunoglobulin; PLEX, plasma exchange.

Older patients as well as those presenting with high disability score were less likely to show significant improvement after a month ( $p=0.004$ and $p=0.008$, respectively). Those who required intubation, as well, showed a lower rate of improvement after a month, where the me- 
Table 2. Disability score progression

\begin{tabular}{|c|c|c|c|c|c|c|c|c|}
\hline Disability score & $4[1]$ & \multicolumn{2}{|c|}{$3[2]$} & $3[2]$ & $2[3]$ & $2[3]$ & $1[3]$ & $1[3]$ \\
\hline Cases, $n$ & 82 & \multicolumn{2}{|c|}{82} & 76 & 75 & 57 & 49 & 49 \\
\hline \multicolumn{3}{|c|}{ Improvement in functional status } & $\begin{array}{l}\text { Cases, } \\
n\end{array}$ & \multicolumn{4}{|c|}{ Proportion of cases with good functional status } & $\begin{array}{l}\text { Sig. } \\
\text { (McNemar's test) }\end{array}$ \\
\hline Improvement fr & eline to & & 49 & \multirow{2}{*}{\multicolumn{2}{|c|}{$\begin{array}{l}\text { 6.8\% at presentation } \\
8.2 \% \text { at presentation } \\
51.0 \% \text { after } 1 \text { month }\end{array}$}} & \multicolumn{2}{|c|}{$73.5 \%$ after 6 months } & $<0.001$ \\
\hline \multicolumn{3}{|c|}{ Improvement from 1 month to 6 months } & 49 & & & \multicolumn{2}{|c|}{$73.5 \%$ after 6 months } & 0.001 \\
\hline
\end{tabular}

Median [IQR].

Table 3. Predictors of disability score improvement at 1 month

\begin{tabular}{lll}
\hline Tests of correlation & Spearman's correlation & Sig \\
\hline Age & -0.328 & 0.004 \\
Days from onset of symptoms & 0.039 & 0.742 \\
Disability score at presentation & -0.305 & 0.008 \\
CSF protein level & -0.081 & 0.591 \\
\hline Tests of association & Category improvement & \multirow{2}{*}{ Sig } \\
\hline Gender & Males 1.5 [2]; females 1 [1] & 0.828 \\
Requiring intubation & Yes 1 [1]; no 2 [1] & 0.004 \\
Type of nerve injury & Normal 2 [2]; axonal 1 [2] & 0.017 \\
& Demyelinating 2 [1] & \\
\hline
\end{tabular}

dian rate of improvement was only 1 [1] when intubated as compared to 2 [1] when not intubated $(p=0.004)$. Cases that had axonal type of nerve injury were less likely to improve compared to cases presenting with demyelinating nerve injury $(p=0.017)$, as shown in Table 3 .

Cases that ended with a better functional outcome up to 6 months after the acute event were younger patients ( $p=0.035$ at 6 months) and those who did not require mechanical ventilation ( $p<0.001$ at 6 months). Demyelinating nerve injury resulted in a better functional outcome at 6 months compared to axonal type of nerve injury $(p=0.034)$.

There is a significant difference in the choice of treatments between the patients who ended with poor outcome and good outcome after 6 months. Most of the cases who had good functional outcome received only IVIG, 25 (69.4\%), in contrast to the use of combination of IVIG and PLEX therapy in majority of cases with poor outcome, 7 (53.8\%), as seen in Table 4.
Lumbar puncture was done around 3.5 [3] days after presentation with protein level averaging on 61.5 [138]. The protein level in CSF positively correlated with the time from onset of symptoms (correlation coefficient $0.445, p$ value $=0.001)$.

\section{Discussion}

GBS is a disease of peripheral nerves, resulting in acute flaccid paralysis. Our current study had a mean age at presentation of $37( \pm 14.4)$, a finding similar to previous studies [11]. Males were the dominant gender reported in our study, with 64 cases (78\%). This finding is supported by several previous studies showing a male predominance $[12,13]$.

The disease presents acutely with rapid deterioration in nerve function and motor power. At presentation, more than half of the cases $(53 ; 64.7 \%)$ were bedbound already (disability scores 4 and 5), a finding similar to previous studies $[11,13]$. Cases presented in our emergency department with an average of 2 days [3] since the onset of their symptoms.

Axonal type of nerve injury was the most common type of injury in our study with 28 cases (34.1\%). This finding is comparable to a reported result in Chinese population [14]. The etiology behind such discrepancy in results can be attributed to genetic and environmental factors [15]. Six cases $(8.5 \%)$ had normal nerve conduction studies, which could be due to early diagnostic workup.

CSF result in all patients showed albuminocytologic dissociation with the level of protein positively correlating with the time of LP (correlation coefficient 0.445, $p$ value $=0.001)$. A study conducted in children showed similar significant finding in patients admitted for less DOI: $10.1159 / 000510443$
Shangab/Al Kaylani 
Table 4. Predictors of poor functional outcome at 6 months

\begin{tabular}{|c|c|c|c|}
\hline Cases, $N$ & 36 & 13 & \\
\hline Age & $39[22]$ & $42[30]$ & 0.035 \\
\hline Gender (male:female) & $26(72.2 \%): 10(27.7 \%)$ & $9(69.2 \%): 4(30.7 \%)$ & 1 \\
\hline Disability score at presentation & $4[1]$ & $5[0]$ & $<0.001$ \\
\hline Time from onset of symptoms until presentation, days & $3[2]$ & $4[4]$ & 0.782 \\
\hline Required mechanical ventilation & $6(16.7 \%)$ & $11(84.6 \%)$ & $<0.001$ \\
\hline \multicolumn{4}{|l|}{ Type of nerve injury } \\
\hline Axonal & $8(22.2)$ & $8(61.5)$ & 0.034 \\
\hline Demyelinating & $13(36.1)$ & $1(7.6)$ & \\
\hline Mixed & $7(19.4)$ & $4(30.7)$ & \\
\hline Not done & $8(22.2)$ & 0 & \\
\hline Combination of IVIG and PLEX & $4(11.1)$ & $7(53.8)$ & \\
\hline
\end{tabular}

$N(\%)$, median [IQR]. IVIG, intravenous immunoglobulin; PLEX, plasma exchange. ${ }^{\text {a }}$ Good functional outcome includes disability score of $0-2{ }^{b}$ Poor functional outcome includes disability score of 3 and above.

than a week [16]. This finding further supports the previously understood disease course and the notion of possible false negative results in early diagnostic workup.

At initial presentation, only $6.8 \%$ of cases were able to walk. This increased to $52.7 \%$ of cases by 1 month. The rate of improvement is higher than the reported improvement in a study done in Iranian population showing a $39.4 \%$ of cases being able to walk after a month, as compared to an initial $15.6 \%$ [13].

After 6 months, follow-up continued to 49 cases only. Of them, $36(73.5 \%)$ were able to walk. The reliability of this finding is questionable as most of the cases that failed follow-up at 6 months went to their home country due to their poor functional status to continue rehabilitation. The proportion, however, is comparable to the outcome in other studies, where $62.9 \%$ of cases were able to walk after 6 months [13]. Multiple factors were found in previous studies to predict the clinical course of the disease and outcome.

Our study demonstrates that an older age at presentation is associated with reduced rate of improvement in disability score after 1 month $(p=0.004)$ and poor functional outcome after 6 months $(p=0.035)$. Older age was also demonstrated in a recent study to correlate significantly with worst prognosis at 1 month [17].

A higher disability score at presentation resulted in both a lower rate of improvement after a month $(p=$
$0.008)$ as well as poor functional outcome after 6 months $(p<0.001)$. Requiring intubation was also noted to be a predictor of poor outcome, with less rate of improvement after a month $(p=0.004)$ and poorer functional outcome after 6 month follow-up $(p<0.001)$. A recent study correlating CRP with disease severity found that the need for mechanical ventilation and a disability score above 4 were associated with higher CRP, and as a result, a more severe disease course as measured by disability score [11].

Cases that had axonal type of nerve injury were less likely to improve than cases presenting with demyelinating nerve injury $(p=0.017)$. They were also less likely to be able to walk after 6 months $(p=0.034)$. This finding in our population is similar to the finding in western populations, where an axonal type of nerve injury carrier has worse prognosis [18]. Eastern Asian populations on the other hand have no significant difference in terms of disease severity and clinical outcome among both types of nerve injury [14].

Poor functional outcome carries morbidity to the patient as well as financial burden to the health care system. It results in a significantly longer duration of hospital stay $(p<0.001)$ as compared to patients with good functional outcome at 1 month. All in all, the rate of improvement from baseline to 1 month and then to 6 months was significant throughout, as demonstrated in Table 3. 
Despite being a monophasic acute illness, resolution is not the rule in outcome. Two-thirds of cases had a minor neurological deficit at 6 month follow-up in an Australian cohort [19]. The data in our study show a significantly less rate of residual deficits with only $37.8 \%$ having residual deficit at 6 months and $34.1 \%$ at 1 year from the onset of illness.

There is a significant difference in the choice of treatments between the patients who ended with poor outcome and good outcome after 6 months of the acute illness. IVIG was the treatment given to most cases who ended with good functional outcome (69.4\%), in contrast to the use of combination of IVIG and PLEX therapy in majority of cases with poor outcome (53.8\%). The explanation to that is that patients with poor outcome have presented with severe disability score, and it was the clinical judgment of the physicians to start more aggressive management, by combination of PLEX and IVIG therapies.

Our study highlights 4 factors as predictors of poor functional outcome after 6 months, including older age, higher disability score at presentation, need for mechanical ventilation, and axonal type of nerve injury. All these findings are supported by previous literature showing their importance in other populations. The study was limited by the small sample size as retrieving older physical files of admissions was not feasible, and by its nature of study design, which included recall bias.

\section{Statement of Ethics}

The study was granted ethical approval from medical education department of Dubai Health Authority. The datasets during and/ or analyzed during the current study available from the corresponding author on reasonable request.

\section{Conflict of Interest Statement}

No disclosure. The authors have no conflicts of interest and consents for publication.

\section{Funding Sources}

The authors did not receive any funding.

\section{Author Contributions}

M.S.: study concept and design; acquisition of data; statistical analysis; analysis and interpretation of data; drafting of the manuscript; and critical revision of the manuscript for important intellectual content. M.K.: study concept and design; drafting of the manuscript; critical revision of the manuscript for important intellectual content; and study supervision.

\section{References}

1 McGrogan A, Madle GC, Seaman HE, de Vries CS. The epidemiology of Guillain-Barré syndrome worldwide: a systematic literature review. Neuroepidemiology. 2009 Feb;32(2): 150-63.

2 Brannagan TH. Intravenous gammaglobulin (IVIg) for treatment of CIDP and related immune-mediated neuropathies. Neurology. 2002 Dec 24;59(12 Suppl 6):S33-40.

3 Buchwald B, Ahangari R, Weishaupt A, Toyka $\mathrm{KV}$. Intravenous immunoglobulins neutralize blocking antibodies in guillain-barré syndrome. Ann Neurol. 2002 Jun 1;51(6):673-80.

4 Cortese I, Chaudhry V, So YT, Cantor F, Cornblath DR, Rae-Grant A. Evidence-based guideline update: plasmapheresis in neurologic disorders: report of the therapeutics and technology assessment subcommittee of the American academy of neurology. Neurology. 2011 Jan 18;76(3):294-300.

5 Meena AK, Khadilkar SV, Murthy JM. Treatment guidelines for guillain-barré syndrome. Ann Indian Acad Neurol. 2011 Jul 1;14(Suppl 1):S73-81.

6 Hughes RA, Raphaël JC, Swan AV, van Doorn PA. Intravenous immunoglobulin for Guillain-Barré syndrome. Cochrane Database Syst Rev. 2014 Sep 19;2014(9):CD002063.
7 van der Meché FG, Schmitz PI. A randomized trial comparing intravenous immune globulin and plasma exchange in Guillain-Barré syndrome. Dutch guillain-barré study group. $\mathrm{N}$ Engl J Med. 1992 Apr 23;326(17):1123-9.

8 van Koningsveld R, Steyerberg EW, Hughes RA, Swan AV, van Doorn PA, Jacobs BC. A clinical prognostic scoring system for guillainbarré syndrome. Lancet Neurol. 2007 Jul 1; 6(7):589-94.

9 Walgaard C, Lingsma HF, Ruts L, van Doorn PA, Steyerberg EW, Jacobs BC. Early recognition of poor prognosis in guillain-barre syndrome. Neurology. 2011 Mar 15;76(11):96875.

10 Hughes RA, Rees JH. Clinical and epidemiologic features of Guillain-Barré syndrome. J Infect Dis. 1997;176(2):92-98. https://doi. org/10.1086/513793.

11 Altaweel YA, Abdelaziz S, Fathy HA, AbdelBadea S. Correlative study between C-reactive protein, clinical severity, and nerve conduction studies in guillain-barrè syndrome. Egypt J Neurol Psychiatr Neurosurg. 2018;54(1):4.

12 Hughes RA, Cornblath DR. Guillain-Barré syndrome. Lancet. 2005 Nov 5;366(9497): 1653-66.
13 Boostani R, Ramezanzadeh F, Saeidi M, Khodabandeh M. A follow-up study on GuillainBarre syndrome and validation of brighton criteria. Iran J Neurol. 2019 Apr 4; 18(2):64-9.

14 Tian J, Cao C, Li T, Zhang K, Li P, Liu Y, et al. Electrophysiological subtypes and prognostic factors of Guillain-Barre syndrome in northern china. Front Neurol. 2019 Jul 2;10:714.

15 Parmar LD, Doshi V, Singh SK. Nerve conduction studies in Guillian Barré syndrome. Int J Neurol. 2013;16(1):1-14.

16 Akbayram S, Doğan M, Akgün C, Peker E, Sayın R, Aktar F, et al. Clinical features and prognosis with Guillain-Barré syndrome. Ann Indian Acad Neurol. 2011 Apr 1;14(2):98102.

17 Tunç A. Early predictors of functional disability in Guillain-Barré syndrome. Acta Neurol Belg. 2019 Dec 1;119(4):555-9.

18 Walgaard C, Lingsma HF, Ruts L, van Doorn PA, Steyerberg EW, Jacobs BC. Early recognition of poor prognosis in Guillain-Barre syndrome. Neurology. 2011 Mar 15;76(11):96875 .

19 Barnes SL, Herkes GK. Guillain-Barre syndrome: clinical features, treatment choices and outcomes in an Australian cohort. Intern Med J. 2019 Nov 24. 